\title{
Preference for punishment of the instrumental or the consummatory response
}

\author{
WARD A. RODRIGUEZ and FRANK A. LOGAN \\ University of New Mexico, Albuquerque, New Mexico 87106
}

\begin{abstract}
In two discriminable runways, rats were punished (shocked) either prior to receiving water reinforcement (punishment of the instrumental response) or after ingesting the water (punishment of the consummatory response). Both forced-choice and free-choice trials were conducted. Results indicate that rats preferred to have the instrumental response punished. It was also observed that the subjects more frequently failed to traverse the runway in which the consummatory response was punished compared to the runway in which the instrumental response was punished. The results were interpreted as being consistent with predictions derived from net incentive theory.
\end{abstract}

The effects of punishing either the instrumental or consummatory response have been investigated for two major reasons. First, there is a theoretical interest concerning whether or not biologically significant or intrinsically reinforcing responses are relatively more resistant to the effects of punishment than are extrinsically reinforced responses (e.g., Estes, 1969; Solomon, 1964). Second, there is concern with how best to punish a response chain or sequence (e.g., Church, 1969; Myer, 1973). Experiments that have directly attempted to ascertain whether punishment of the instrumental or the consummatory response more effectively suppresses ongoing behavior have generally produced conflicting results. For example, Church (1969) and Walker, Popovich, and Derby (Note 1) concluded that punishing the instrumental response suppressed behavior to a greater degree than did punishing the consummatory response. Myer (1973) concluded that there was no difference between punishing these types of responses, while Bertsch (1972) found that punishing the consummatory response more effectively suppressed behavior than did punishing the instrumental response.

A major problem with these studies and with related research is the lack of consensus of what it means to punish the consummatory response. Consequently the operations used in these studies are often not comparable. In some instances, the "consummatory response" is punished before the subject receives reward (e.g. Bertsch, 1972, Experiment 1; Church, 1969; Walker et al., Note 1) and at other times, after the subject receives the reward (e.g., Bertsch, 1972, Experiment 2; Myer, 1973).

This research was supported by a grant from the National Science Foundation to Frank A. Logan and a National Institute of Health predoctoral fellowship to Ward A. Rodriguez. Reprints may be obtained from Ward A. Rodriguez, Department of Behavioral Sciences, New Mexico Highlands University, Las Vegas, New Mexico 87701.
It is our contention that the temporal order of rewards and punishments, as stressed by Solomon (1964), determines whether or not the consummatory response is optimally punished. Thus, punishment of the instrumental response would occur according to the following sequence of events: instrumental response, aversive stimulus, reward available, consummatory response. The consummatory response would be punished after the subject had ingested the reward, yielding the following sequence: instrumental response, reward availability, consummatory response, aversive stimulus.

Using the temporal sequences described, Solomon (1964) predicted that more suppression would occur with punishment of the consummatory response. He reasoned that aversive emotional reactions would become more easily associated with the punished consummatory response than with the instrumental response. Our theoretical interpretation and predictions are similar to Solomon's. When shock and water occur in the same situation, the positive incentive value of the water reward and the negative incentive value of the shock combine to give the net incentive value for completing the response. Thus, when an aversive stimulus is followed by a reward (i.e., the instrumental response is punished), the aversive stimulus becomes associated with the reward and hence the aversiveness of that stimulus is attenuated. In contrast, when a reward is followed by an aversive stimulus, the reward becomes associated with the aversive event and the positive incentive value of the reward is attenuated. As a result of the two operations, there is a greater amount of positive incentive when the instrumental response is punished than when the consummatory response is punished. An experiment showing that rats prefer to have the instrumental rather than the consummatory response punished would lend credence to this interpretation.

To date, researchers investigating the effects of 
punishing either the instrumental or consummatory response have used time-dependent measures. However, Logan (1960) and others have shown that various local factors can influence speed or rate measures. Since such measures of responding are learnable, they are often confounded indices of incentive motivation. The major purpose of the present experiment was to examine the effects of different rewardpunishment sequences using choice as the measure of relative incentive. Either the instrumental approach response or the consummatory response was punished in discriminably different alleys to determine which punishment sequence produced greater behavioral suppression. In order to assess the relative incentive value of the two procedures, the subjects were allowed, on some trials, to choose which response would be punished.

\section{METHOD}

\section{Subjects}

The subjects were 10 male Long-Evans hooded rats obtained from Simonsen's laboratory in Gilroy, California; they were about 100 days old at the start of the experiment. They were housed in individual cages and maintained at approximately $80 \%$ of their free-feeding weights by restricting water intake; food was available ad lib. A 12-h light-dark cycle was maintained in the animal housing area. The subjects were tested during the light phase of the diurnal cycle. Two subjects died of a staph infection during Phase 5. Their data were omitted from analyses of Phase 5 results.

\section{Apparatus}

The apparatus consisted of three parallel alleys, each $2.44 \mathrm{~m}$ long $\times 10.5 \mathrm{~cm}$ wide $\times 15 \mathrm{~cm}$ high, covered with clear Plexiglas hinged lids. Walls of clear Plexiglas were backed by black construction paper on the two outside alleys, while the middle alley's walls were backed by white construction paper. A metal floor, painted the same color as the walls, ran the first $1.83 \mathrm{~m}$ of each alley. A manually controlled guillotine door cut off the $.61-\mathrm{m}$ goalbox from the rest of the alley and prevented retracing once the subject entered the goalbox. The goalbox was covered with a grid floor consisting of $.6-\mathrm{cm}$ stainless steel rods, $.3 \mathrm{~cm}$ apart. A $.05-\mathrm{mA} 150$-msec shock could be delivered to the grids by a GrasonStadler shock generator (Model E6018A). At the end of the goalbox was a brass water cup into which $.30 \mathrm{ml}$ of water was delivered by a solenoid-operated water dispenser.

An $18.5 \times 7.5 \times 7.5 \mathrm{~cm}$ startbox with spring-loaded door and an $11 \times 10.5 \times 17.5 \mathrm{~cm}$ alley extension, both of burnished aluminum, opened onto the alleys. Both the startbox and alley extension could be positioned directly in front of the alleys during forcedchoice trials or at an intermediate position so that during freechoice trials the subject could view both a black and white alley simultaneously.

Photocells were positioned as follows: $11 \mathrm{~cm}$ from the start door (the beginning of the alley), after the first $197.8 \mathrm{~cm}$, after the first $213.5 \mathrm{~cm}$ of the alley, and $1.6 \mathrm{~cm}$ from the end of the alley. This last photocell was positioned such that the subject broke the beam as the subject's head entered the water cup and closed after the subject withdrew from the cup. All times were recorded by a $.01-\mathrm{sec}$ standard timers.

The entire alley was suspended inside a box, $3.66 \times .91 \times .91 \mathrm{~m}$; five sides of the box were sheet metal and the top was translucent blue Plexiglas. Indirect illumination was provided by a neon lamp. With the room darkened and the neon lamp on, the translucent Plexiglas functioned as a one-way viewer. Two exhaust fans masked extraneous noise and provided ventilation.

\section{Procedure}

Pretraining began 2 weeks before appetitive alley training. During this time, the subjects were handled and placed on the waterdeprivation schedule. Nine to 14 days prior to alley training, the subjects were allowed to explore the alley with the doors ajar. During the next 8 days, they were also water-magazine trained. All subjects were trained in all alleys.

All subsequent phases of the experiment followed the same general running schedule (Logan, 1969). Each subject was run six trials a day; the first four trials were forced-choice trials, with two trials in a black alley and two trials in the white alley. The fifth trial was a free-choice trial in which the subject could choose whether to traverse the black or the white alley. Trial 6 was a forced-choice trial in which the subject was forced into the alley opposite to that chosen on Trial 5. The first four forced-choice trials were determined by one of the following sequences: LLRR, LRRL, RLLR, RRLL. One of these four sequences was presented each day according to a random schedule. Position cues were made irrelevant during the free-choice trials by randomly positioning the black alley to either the right or left side of the white alley, with the restriction that there be an equal number of placements to the right and left of the white alley during each experimental phase,

Prior to the beginning of a trial, the subject was placed in a neutral waiting box for $2 \mathrm{~min}$. The subject was then placed in the start section of the apparatus, the startbox door was released, and the subject was given $180 \mathrm{sec}$ to traverse each alley section. If a subject failed to traverse a particular alley section within $180 \mathrm{sec}$, it was picked up and returned to the waiting cage for the next trial and a 180 -sec score was assigned for that section and all forward alley sections, if any.

Start time on forced-choice trials and choice time on free-choice trials was defined as from the time the startbox door opened until the subject broke the first photobeam. The second, third, and fourth photocells measured run time, goalbox time, and watercup approach time, respectively. The number of times the subject's head entered the water cup during a trial was also recorded. Once the water-cup beam was broken, the subject was left in the goalbox approximately $20 \mathrm{sec}$. The intertrial interval was $2-8 \mathrm{~min}$. All times were converted to their reciprocals.

The experiment contained five phases. During Phase 1, all subjects were trained to traverse both the black and white alleys according to the daily trial procedure. Shock was never delivered during this phase, and each traversal of the alley was rewarded with $.30 \mathrm{ml}$ of water. This phase continued for 24 days. Phase 2 , which involved differential instrumental conditioning, began on Day 25, when the instrumental approach response was punished in the white alley and the consummatory drinking response was punished in the black alley. In this phase, which lasted 6 days, breaking the photocell $7.5 \mathrm{~cm}$ in front of the water cup resulted in punishment of the instrumental response. In the black alley, the consummatory response was shocked $.75 \mathrm{sec}$ after the subject's head came out of the water cup. Shock was presented on all six trials each day; the appetitive reward remained the same as in the training phase.

As all subjects' responses were severely suppressed during Phase 2, the animals were retrained in Phase 3 to traverse the alleys according to the original training procedure. Again, each traversal was rewarded with $.30 \mathrm{ml}$ of water and shock was not presented. Phase 3 lasted 30 days. Phase 4 was identical to Phase 2, the instrumental approach response being punished in the white alley and the consummatory drinking response punished in the black alley. Phase 4 was continued for 36 days. During the last 78 days of the experiment, Phase 5, the alley-brightness responsepunishment contingency was reversed. Thus, a traversal of the white alley resulted in punishment of the consummatory response, while punishment of the instrumental response occurred in the 
black alley. The shock paramenters and the reward were identical to those employed in Phases 2 and 4.

\section{RESULTS}

During Phases 1 and 2, the proportion of trials on which the subjects chose the white alley was .57 and .52 , respectively. The proportion of choices to the white alley for the last 12 sessions of Phase 3 was .54 . These data suggest that the subjects had no tendencies to choose the white alley over the black alley prior to Phase 4.

Figure 1 presents the free-choice data during Phase 4 and 5 , the phases during which extended shock trials were given. It is clear that, given a choice, the subjects preferred to have the instrumental response punished during both Phase 4 and Phase 5. A comparison of the proportion of choices (employing the arcsine transformation as suggested by Kirk, 1968) made to the white alley during the last 12 sessions of Phase 3 (reestablished baseline) with the proportion of choices during the last 12 sessions of Phase 4 showed that the subjects increased responding to the white alley $[\mathrm{t}(9)=3.027, \mathrm{p}<.015]$. This last result also indicates that the animals developed an absolute preference for the white alley during Phase 4 .

The Phase 5 choices of the animals were also for punishment of the instrumental approach and not the consummatory response. Comparing performance on the first 12 sessions of Phase 5 with the last 12 sessions of Phase 5 showed that the subjects increased preference for the black alley $[\mathrm{t}(7)=3.587, \mathrm{p}<$ .009]. Further, it was also found that, over the last 12 sessions of Phase 5, this preference was significantly greater than $.5[\mathrm{t}(7)=2.621, \mathrm{p}<.034]$.

Figure 2 depicts the proportion of alley nontraversals during both free- and forced-choice trials to

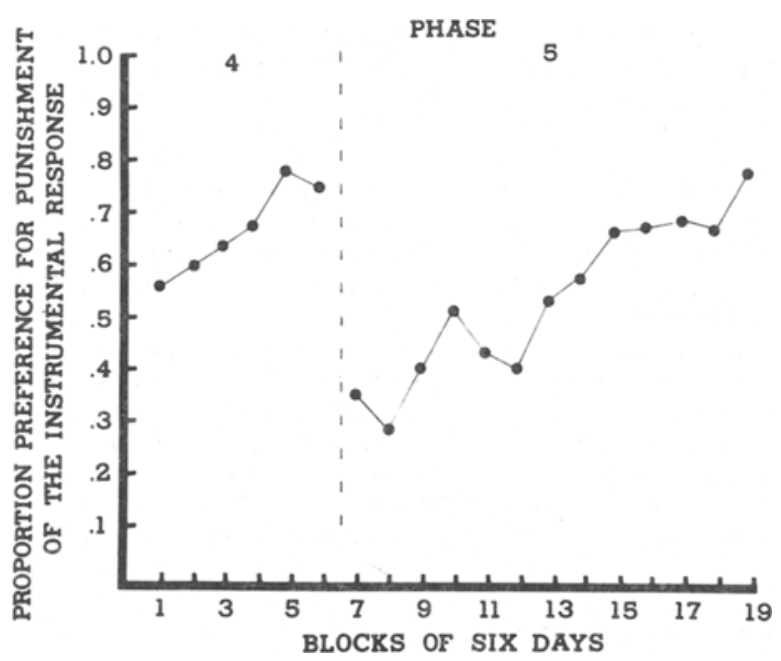

Figure 1. The proportion of choices of the runway leading to punishment of the instrumental response during Phases 4 and 5.

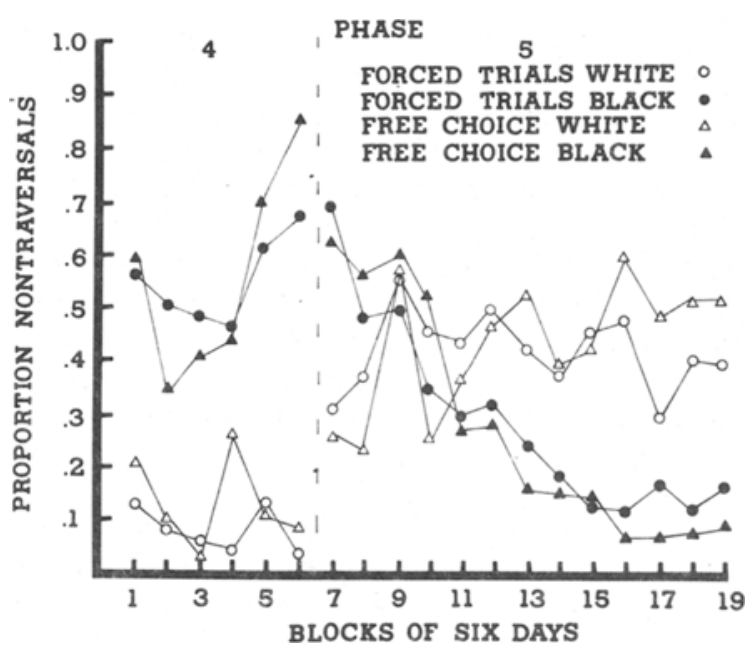

Figure 2. The proportion of trials on which the subjects failed to traverse the runway during Phases 4 and 5 . Forced-choice trials (Trials 1-4) are plotted individually from free-choice trials (Trial 5).

each alley over the last two experimental phases. Most interesting is the finding that the alley in which the consummatory response was punished was not traversed a great proportion of the time, compared to the proportion of nontraversals in the alley in which the instrumental response was punished. Moreover, this effect occurred during both Phase 4 and Phase 5 , as reflected by an analysis of the proportion of nontraversals to the white and black alleys during the forced-choice trials of Phase $4[\mathrm{t}(9)=8.43, \mathrm{p}<$ $.001]$ and the last 36 sessions of Phase $5[t(7)=2.578$, $p<.037]$. Analyzing the proportion of nontraversals to each alley on the free-choice trials of Phase 4 and the last 36 sessions of Phase 5 demonstrate that even on free-choice trials the animals failed to traverse the alley in which the consummatory response was punished more than the alley in which the instrumental response was punished $[\mathrm{t}(9)=5.035$, $\mathrm{p}<.001$, Phase $4 ; \mathrm{t}(7)=2.444, \mathrm{p}<.045$, Phase 5]. It should be noted that only rarely (on about $3 \%$ of the trials) did the animals fail to traverse the alley during the last 12 sessions of Phase 3 . Nontraversals on Trial 6 are not presented, since the subjects were forced in the opposite direction from Trial 5 and, therefore, might not be balanced across alleys. Nevertheless, all preliminary analyses suggest that nontraversal performance on Trial 6 is comparable to that of the other five trials. These results are more striking than the free-choice data in suggesting that the subjects preferred to be punished for the instrumental rather than the consummatory response. The subjects often chose not to completely traverse the alley in which the consummatory response was punished, and this occurred even when the subject initially chose the alley in which the consummatory response would be punished. These nontraversal results, in conjunction with the observation that a number of 
subjects supposedly punished for the consummatory response actually lifted their heads out of the water cup to be punished and subsequently reentered and ingested the water, may have attenuated the robustness of the free-choice measure. That is, regardless of the alley chosen on a free-choice trial, the subject could, and often did, avoid having the consummatory response punished either by failing to traverse the alley or by lifting its head out of the water cup prior to ingesting the water.

Finally comparison of Figures 1 and 2 suggests that the nontraversal measure more quickly revealed the effect of the reward-punishment temporal sequence on behavior than did the free-choice measure.

Since the proportion of subjects failing to complete the alley response was rather high, the speed data will not be reported. Nevertheless, these data are consistent with the choice and nontraversal data in that the rats ran faster in the alley associated with the instrumental response.

\section{DISCUSSION}

The present data strongly support the conclusion that punishment of the consummatory response is more disruptive than comparable punishment of the instrumental response. Both the time-independent choice and the time-dependent speed measures were consistent in supporting this conclusion. Moreover, the finding that subjects often learned to receive shock prior to consuming the water, even when the consummatory response was programmed for punishment, further supports this conclusion. It should be noted that the decreased propensity to traverse the alley in which the consummatory response was punished necessarily reduced the number of shocks paired with that alley. Nevertheless, the subjects still chose to have the instrumental response punished.

The data from this experiment closely agree with predictions derivable from Logan's $(1968,1969)$ differential, or net incentive, theory. According to this theory, punishment of the consummatory response results in water signaling shock and thus, to some degree, becomes less desirable. On the other hand, when the instrumental response is punished, the aversive properties of shock are attenuated, since shock acquires some of the desirable properties of the water reward. The net incentive value for making the instrumental response is thus greater than that for making the consummatory response. This interpretation, it should be noted, rests upon the well-supported notion that forward conditioning is more robust than backward conditioning (Mackintosh, 1974).

Estes' (1969) stimulus amplifier theory is also consistent with these results, Using Estes' terminology, when an aversive stimulus is followed by a reward, a large number of amplifier elements associated with reward become associated with the aversive stimulus. Hence, it is found (Church, 1969) that punishing the first response after a subject is rewarded more seriously disrupts performance than punishing the last response in the chain. These results are consistent with Logan and Estes because when the first response is punished, the appetitive reward signals shock and may therefore acquire some of the aversive or negative incentive value of shock.

Although the present experiment provides evidence that punishing the consummatory response is more suppressive than punishing the instrumental response, there are undoubtedly conditions under which this result would be reversed. The incentive value (Logan) or positive drive (Estes) for making a particular response is determined by the conditions of reinforcement (e.g., amount, delay). By delaying punishment of the consummatory response, we might reverse the preference data presently reported. In short, the relative effects probably depend upon the interaction of the parameters of reward and punishment as well as on their sequence.

\section{REFERENCE NOTE}

1. Walter, L. C., Popovich, B. G., \& Derby, T. R. Intermittent and continuous punishment of operant and consummatory behov. iors. Paper presented at 81 st Annual Convention of the American Psychological Association in Montreal, Canada, August 1973.

\section{REFERENCES}

Bertsch, G. J. Punishment of consummatory and instrumental behavior: Effects on licking and bar pressing in rats. Journal of Comparative and Physiological Psychology, 1972, 78, 478-484.

Church, R. M. Response suppression. In B. A. Campbell \& R. M. Church (Eds.), Punishment and aversive behavior. New York: Appleton-Century-Crofts, 1969.

Estes, W. K. Outline of a theory of punishment. In B. A Campbell \& R. M. Church (Eds.), Punishment and aversive behavior. New York: Appleton-Century-Crofts, 1969.

KIRK, R. E. Experimental design: Procedures for the behavioral sciences. Belmont, Calif: Brooks/Cole, 1968.

LOG AN, F. A. Incentive. New Haven: Yale University Press, 1960.

LogAn, F. A. Incentive theory and changes in reward. In K. W. Spence \& J. T. Spence (Eds.), The psychology of learning and motivation (Vol. 2). New York: Academic Press, 1968.

Logan, F. A. The negative incentive value of punishment. In B. A. Campbell \& R. M. Church (Eds.), Punishment and aversive behavior. New York: Appleton-Century-Crofts, 1969.

Mackintosh, N. S. The psychology of animal learning. New York: Academic Press, 1974.

MYER, J. S. Effects of punishing elements of a simple instrumental-consummatory response chain. Journal of the Experimental A nalysis of Behavior, 1973, 19, 251-257.

Solomon, R. L. Punishment. American Psychologist, 1964, 19 , 237-253.

(Received for publication May 11, 1978; revision accepted May 14, 1979.) 